\title{
An Enveloped Auricular Prosthesis for Ear Defect: A Clinical Report
}

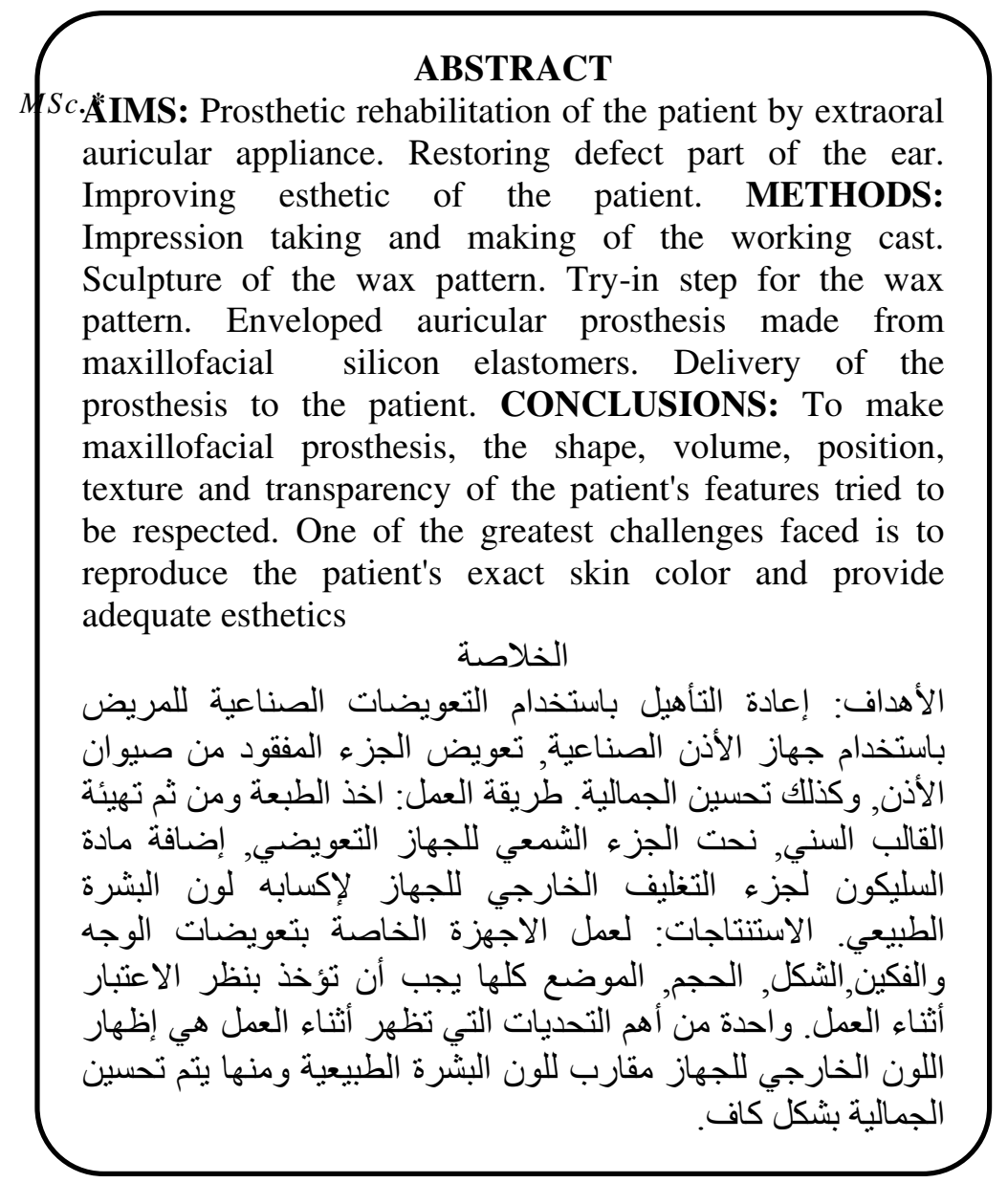

Nadira A. Hatim. $B D s$,

Salem Hazem $B D s . * *$

Mohammed A. Abdulla.

$B D s, M S c . \dagger$

\begin{abstract}
* Professor. Prosthetic department, college of dentistry, Mosul university, Iraq

** Dental student in diploma of prosthetic dentistry. Prosthetic department, college of dentistry, Mosul university, Iraq

$\dagger$ Assistant. Lecturer. Prosthetic department, college of dentistry, Mosul university, Iraq
\end{abstract}

oss of parts of the head and neck can be caused by surgery, trauma, or developmental malformations. Despite improvements in reconstructive

and plastic surgery, replacement of the more intricate facial structures still requires the use of man-made materials as external prostheses ${ }^{(1)}$. The creation of a life-like prosthesis requires considerable skill and expertise ${ }^{(2)}$.

The extrinsic and intrinsic coloration of maxillo-facial silicone elastomers has always been a challenge for the clinician in order to obtain a perfect, durable integration with the surrounding skin tissues ${ }^{(3)}$. Frequently, conventionally retained facial prostheses are the most practical, trouble free, cost efficient, and successful types of prostheses ${ }^{(4)}$.

Surgical reconstruction poses a challenge to the surgeon due to the complexity of the human ear's shape and size. Another option is to design an auricular prosthesis, which usually offers a better morphologic result ${ }^{(5)}$. It is important that the patient is informed about the possible outcome related to the esthetics ${ }^{(6)}$.

Superior color match and patient acceptance, especially in nasal or auricular prostheses, make prosthetic rehabilitation superior to the surgical approach, especially if the defect is 
large in size ${ }^{(7)}$. The use of extraoral fixtures as bone anchorage was introduced many years ago and since then many patients were rehabilitated with better results ${ }^{(8)}$.

The purpose of this report to resolve a special design to envelope the defect and construct the acceptable retention of artificial ear.

\section{Case history:}

A 35-year-old man was referred to the Department of Prosthodontics, college of dentistry, university of Mosul for prosthetic rehabilitation one year after explosion accident, due to the explosion the postero-infeior half of his external ear was missed (Fig.1).

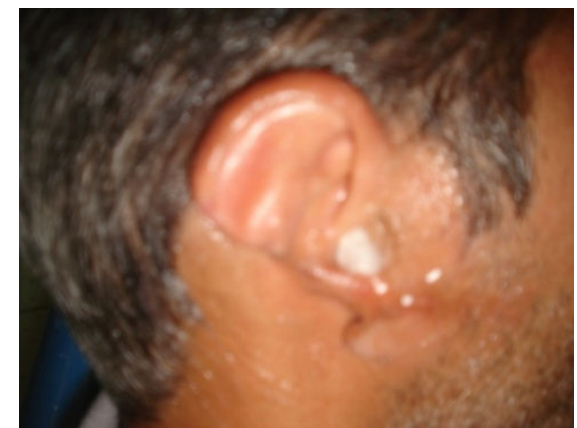

Figure (1) Injured left ear ear

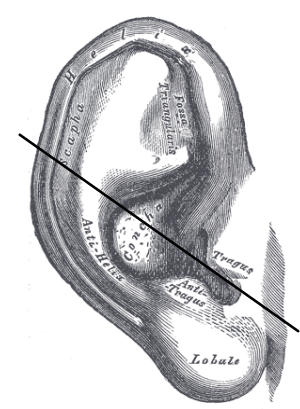

Figure (2) Extension of missing parts of the

On examination, the defect extended from the middle of the helica to the middle of the scapha passing through the centre of concha Anterior to antitragus (Fig.2). Due to the financial reason the patient could not receive a plastic surgery or implant for the retention. The defect was evaluated to identify possible restorative limitations regarding retention and esthetics.

The decision were taken to restore the defect by auricular prosthesis made from silica by mechanical retention (enveloping the remaining part of the defect ear) and adhesive.

\section{Procedure:}

\section{- Impression making:}

Impression for injured and contra lateral ear were taken by alginate impression material (Kromopan, Italy) after boxing with utility wax (B.M.S.modeling wax, Italy) (Fig. 3). Irreversible hydrocolloid impression mixed in a thin consistency and applied to the defect area to facilitate flow of impression material within tissue undercut. After setting the impression material adequate layer of gypsum plaster applied to form the base for stabilizing the impression to be poured by using dental stone for making the working cast.

After boxing of the impressions the cast were poured by dental stone (Zeta plus, Italy) (Fig. 4). 


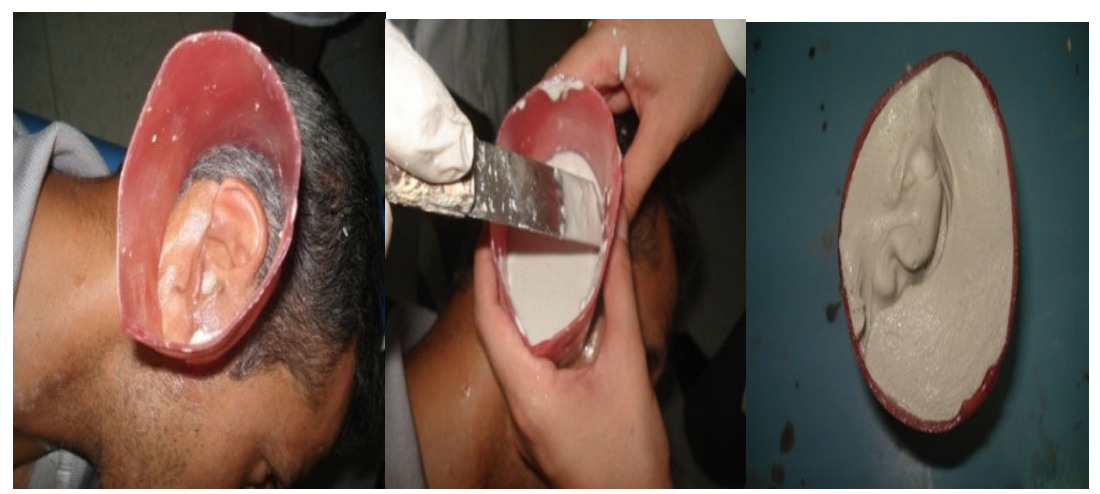

Figure (3) Impression of the external ear with boxing.

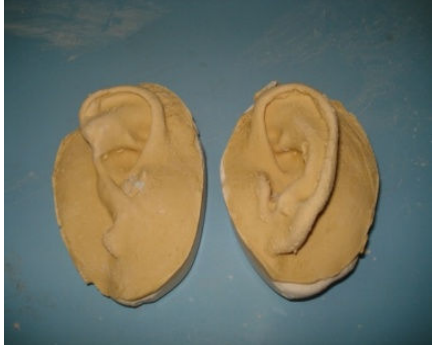

Figure (4) Stone model of injured and contra-lateral ear

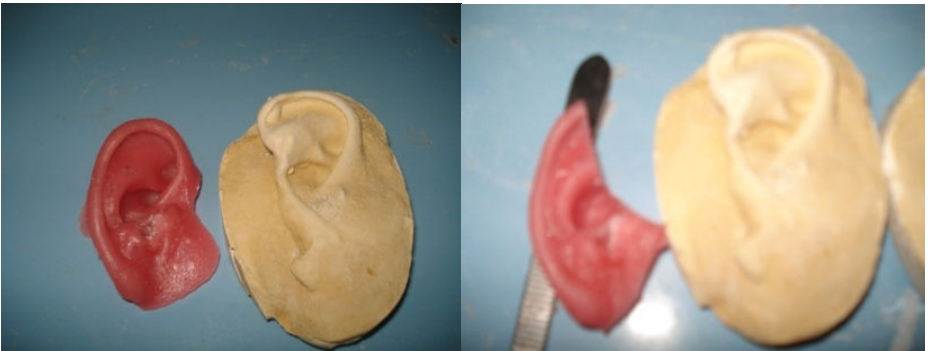

Figure (5) Wax donor ear and adaptation to the cast

\section{- Preparation of wax pattern:}

Using the "donor technique,' in which a relative with ear contours that closely mimic those of the patient acts as the donor to make an ear impression. By using the impression of donor right ear, a melted utility wax were poured and leaved to cool, after getting the wax model we cut the postero-infirior part of the wax ear then we adapted this part to the cast model of defected patient ear (Fig. 5). Matching with the contra-lateral cast model the wax were carved to get asymmetry, green cast wax( Dentaurum, Germany) adapted on the stone model as an extension to the defect. The red wax is saperatable from the cast (Fig. 6)

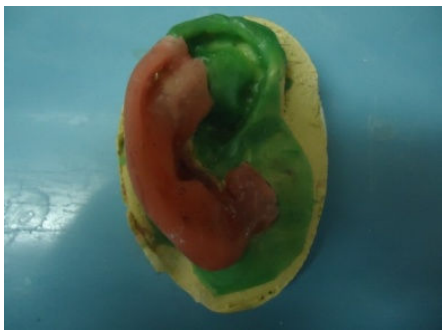

Figure (6) Green cast wax in adapted as an extension

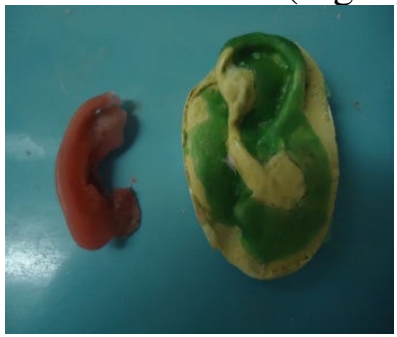

Figure (7) Separateable red part for try

\section{Try in of the wax pattern:}

The red part was separated in order to detect the accuracy of wax pattern on patients ear to insure adaptation and achieve retention (Fig.7). After ensuring the final esthetic result, the red part seal to the green part on the cast, the wax pattern then finished and polished (Fig. 8). Then the model were flasked using dental stone and putty index (Vertex, Netherlands) and the wax eliminated (Fig. 9) 


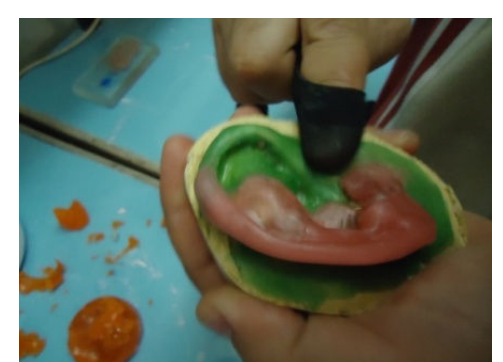

Figure (8) Sealing and finishing of the wax pattern

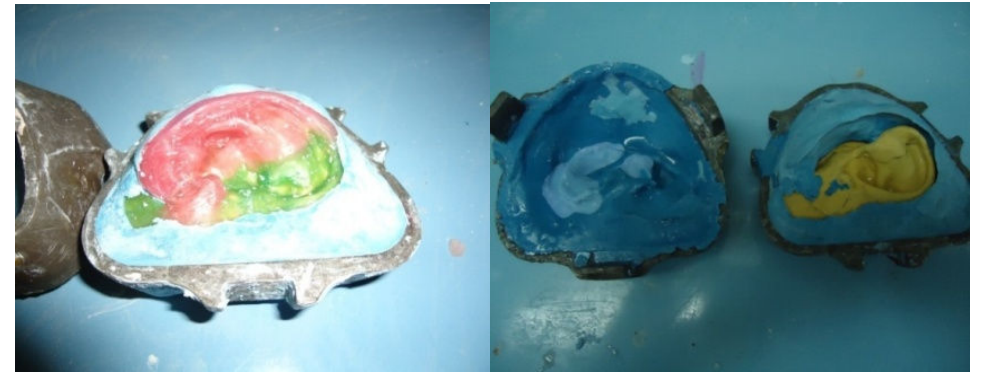

Figure (9) Flasking of the model

\section{- Color selection:}

Using the basic color of the silicon kit( polymerkits, United Kingdom) the color of the mix match with the color of the contra-lateral ear (Fig.10).

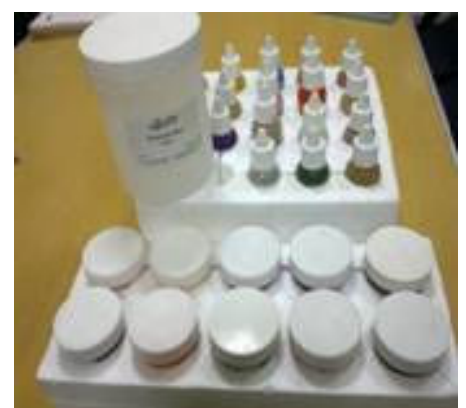

Figure (10) Basic color of silicon kit

\section{- $\quad$ Silicon curing:}

According to manufacture advisements the A and B parts mix in a percentage of $1 / 10$ and the mix packed in the flask model to cure by long cold method for 24 hours. The silicon appliance then deflasked finished by cutting the excesses cheerfully using a sharp blade the prosthesis then delivered to patient with instruction for using and maintenance (Fig. 11).

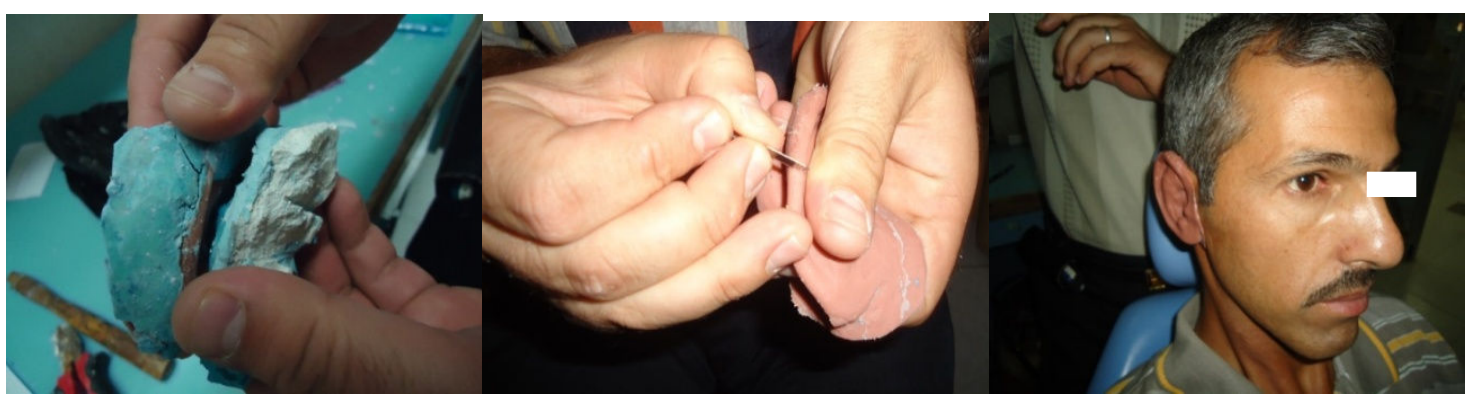

Figure (11) Defasking and finishing of the prosthesis

\section{DISCUSSION}

The process of creating a silicone auricular prostheses provide a cost effective and cosmetically acceptable means of camouflage for patients who decline or postpone surgical reconstruction ${ }^{(2)}$. High accuracy in morphology and positioning can be achieved by finer CT scanning. The haptic CAD system eased the design (to match the morphology of the deficient side), and smoothing of the final auricular prosthesis model ${ }^{(9)}$.

Bone-anchored titanium implants may provide patients with a safe and reliable method for anchoring auricular prostheses that enables restoration of their normal appearance and 
offer an improvement in their quality of life. Hence, the use of bone-anchored prostheses should be considered to be a viable alternative to surgical reconstruction ${ }^{(10)}$. In this case the patient didn't agree for implant retention due to financial reason. The success of most maxillofacial prostheses depends on retention by medical adhesives in addition to the undercut and friction of extensions.

Unfortunately, all of the methods used to choose pigments for this maxillofacial prostheses are dependent upon the human eye for discrimination. Not only is it difficult to compare colors by visual methods, it is also difficult to determine which pigments should be used and in what amount to achieve an adequate color match in addition to the changes of silicon color after crystallization.

\section{CONCLUSIONS}

To make maxillofacial prosthesis, the shape, volume, position, texture and transparency of the patient's features tried to be respected. One of the greatest challenges faced is to reproduce the patient's exact skin color and provide adequate esthetics. Although the objective of a facial prosthesis is to fulfill the patient's esthetic needs and to improve his/her quality of life, the limitations of this material in exactly simulating natural features after finishing the prosthesis.

\section{REFERENCES}

1. Khan Z, Gettleman L, and Jacobsen C. Conference Report: Materials Research in Maxillofacial Prosthetics $J$ Dent Res. 1992:1541-1542.

2. Butler D, Gion G, and Rapini R. Silicone auricular prosthesis. J Am Acad Dermatol. 2000; 43:687-90.

3. Ciocca L, Gentile L, Scotti R. New aesthetic results with auricular prosthesis: two case reports. Minerva Stomatol. 2003;52(10):435-40.

4. Lemon J, Kiat-amnuay S. Gettleman L, Martin J, and Chambers M. Facial prosthetic rehabilitation: preprosthetic surgical techniques and biomaterials Current Opinion in Otolaryngology \& Head and Neck Surgery 2005;13:255-262.

5. Ting J, Fuqiang Z, Xuemei H, Chengtao W. Design and Fabrication of Auricular Prostheses by CAD/CAM System. School of Mechanical Engineering Shanghai, China. 2007

6. Mancuso D, Goiato M, Dekon S, Gennari-Filho H. Visual Evaluation of Color Stability after Accelerated Aging of Pigmented and Nonpigmented Silicones to be used in Facial Prostheses. Indian J Cancer. 2009; 20 (1): 77-80.

7. Kharchaf M. Maxillofacial Prosthetics, General Principles HONcode principles of the Health On the Net FoundationUpdated: 2010: 5.

8. Dib L, De Oliveira J, Neves R, Sandoval R, Nannmark U. Auricular rehabilitation by means of bone grafting from the iliac crest in combination with porous extraoral implants: a case report. Clin Implant Dent Relat Res. 2007; 9(4):228-32.

9. Subburaj K, Nair C, Rajesh S, Meshram S, Ravi B. Rapid Development of Auricular Prosthesis using CAD and Rapid Prototyping Technologies Int. J Oral Maxillofac Surg. 2007; 36: 938-943.

10. Gumieiro E, Dib L, Jahn R, Junior F, Nannmark U, Granström G, Márcio C. Bone-Anchored Titanium Implants for Auricular Rehabilitation: case report and review of literature. Sao Paulo Med J.2009;127(3):160165. 